Chapter 5

\title{
Biochemical and Surgical Aspects of Epilepsy Related to Brain Tumors - Appraising Redox Biology and Treatments
}

\author{
Pinar Atukeren, Taner Tanriverdi and \\ M. Ramazan Yigitoglu
}

Additional information is available at the end of the chapter

http://dx.doi.org/10.5772/58343

\section{Introduction}

Oxidative stress appears when prooxidant-antioxidant balance is altered in the direction of the former, causing neuronal cell death and dysfunction, so resulting in oxidative damage lending to disease pathogenesis. Brain tissue have a very high metabolic rate as it consumes approximately $20 \%$ of the inhaled oxygen due to the fact that neurons need high amounts of ATP for sustaining ionic gradients across cell membranes and so as for neurotransmission and as most of the ATP is produced via oxidative metabolism, neurons are dependant on mitochondrial function supremely. Oxidative stress is known to act a part in mitochondrial dysfunction and brain damage associated with epileptic seizures. In recent studies it is implied that epileptic status alters the redox potential and diminishes ATP levels creating a break down in brain energy production and a damage to cellular targets such as protein, lipids and DNA is seen following persistent seizures. Thus a consecutive cell damage emerges after persistent seizures with an increase in mitochondrial oxidative stress status in epilepsy patients.

Brain tumours typically cause epileptic seizures. The life quality of patients with brain tumors having epileptic seizures are seriously effected owing to the factors not being clear and the problems confronted in the treatment. Antiepileptic treatment culminates with limited success due to drug interactions, adverse effects and pharmacoresistance frequently. The mechanism of epileptogenesis in patients having a brain tumour is not clarified obviously yet. Seizures are conferred as the initial symptom in around $30-50 \%$ of patients particularly with slow growing primary brain tumors [1]. Seizures are mostly seen in patients having low grade tumors while in patients with high grade brain tumors the insidance is lower. Also, the location of the tumor 
is an important deterministic of epileptic seizures. Due to the decreased intratumoral perfusion and increased metabolism, hypoxia occurs causing acidosis through metabolic requirements of the proliferating tissue and the disrupted oxidative energy metabolism, both inducing glial cell swelling and damage effecting the surrounding tissue [2]. It was implied that derangement between the excitatory and inhibitory balance leads to glioma associated seizures as there is an intimate relationship between seizure activity and increased extracellular glutamate levels in tumor related epilepsy. The involvement of tumor growth is not clear yet. Glutamate levels are shown to increase reaching neurotoxic levels during seizures. Epileptic activity is implied to be originating within the peritumoral border distant from the tumor tissue and it was shown that the glutamate levels were higher in peritumoral cortex when compared with health brain tissue parts in glioma patients. GABA receptor activity is thought to be an inhibitor as receptor down regulation seems causing hyperactivity in the surrounding microenvironment. There is also a close relationship between immunological and inflammatory changes with a diminished risks of glioma and epileptic seizures related to tumor presence as proinflammatory cytokines seem to be involved in epilepsy pathogenesis [3,4]. On the other hand, patients having epileptic seizures with brain tumors were reported having increased levels of ROS and the antioxidant status was found to be decreased. This seems to be recovered after treatment with antiepileptic drugs favoring the so called damaging effect of oxidative stress in epilepsy flashing the estimated possibility of preventing the seizures via antioxidant treatment. Alleviation of the oxidative damage utilizing antioxidant substances in epilepsy was shown experimentally.

These knowledge may highlight the possible future strategies in the medical treatment of tumor associated epilepsy. In terms of surgical aspects, removing the tumor to stop epileptic seizures might not assure a prosperous result alone considering that the neurons surrounder the tumor form an epileptogenic area [2]. On the other hand, when the lesion is removed, surrounding neurons may stop exciting aberrantly, returning to normal status. Thus the neurosurgeons are suggested to minimize the residual tumor volume where applicable. The conservation of the mitochondria and eventually decreasing oxidative stress related events seems to be reasonable therapeutic approach. Not only resecting the tumor but also combining an appropriate postoperative treatment should be the main aim in seizure control. As mentioned, therapy with antioxidants having a potential neuroprotective effect, should be intended to lower the conferred oxidative damage in epilepsy treatment where ketogenic diets were also shown to have beneficial effects in treating epileptic seizures as they seem to increase glutathione levels in mitochondria. It is clear that developing a mitochondria targeted antioxidant therapy would be promising approach in epilepsy, hopefully resulting in seizure control withdrawing treatment with antiepileptic drugs in long term.

\section{The biochemical mechanisms transpiring in case of epileptic seizures}

Epilepsy should be considered not only as a single disease, but also common symptomatic symptoms of brain abnormalities involving central nervous system infections, traumatic brain injuries, genetic syndromes or brain lesions such brain tumors are present. The relationship of inflammation in the pathophysiology of epilepsy is implied in various clinical studies $[5,6]$. 
The dysregulated homeostasis in the peritumoral tissue may cause to seizure somethesia as the tumor cells create an intrinsic epileptogenicity. The most vital mechanism inducing tumor related seizures is the alteration of amino acid neurotransmission where also an alteration in the extracellular ions is involved. These mechanisms should be enlightened to provide guidance for improving new strategies in the surgical and medical treatment for tumor associated epilepsy.

The tumor tissue might be epileptogenic due to excreting some molecules itself or the peritumoral tissue might be transformed into an epileptogenic zone as the microenvironment of brain tumors is considerably different from that of healthy brain tissue which is demonstrated via contemporary imaging techniques. On the other hand, the peritumoral tissue might turn into an epileptogenic zone because of the mechanic restrainment of the tumor as a result of hypoxia and ischemia. These lead to epileptic seizures following the alterations in neurotransmitters and their receptors, metabolic changes and inflammatory responses. Structural epileptogenic abnormalities in the cortex might also be attended as low levels of $\mathrm{N}$-acetylaspartate which is a marker for the survival and functionality of the neurons, was shown in the epileptogenic cortex via magnetic resonance spectroscopy [7]. It was shown that damage in the subcortical network affecting the electrical transmission is effectuated mostly by high grade brain tumors [8] while a partial deafferentation in cortical regions is induced by low grade tumors causing an epileptogenic stage $[9,10]$. Inflammatory changes and gliosis in the peritumoral tissue also contribute. Derangements in the neurovascular entirety also cause hypersynchronization leading to epileptogenity. The emerge of decreased expression of junctional transmembrane proteins [11] and increased vascular endothelial growth factor (VEGF) release which aggrevates the edema in the surrounding of the lesion [12] is due to the impaired blood brain barrier through molecular alterations in brain tumors and hypoxia and acidosis, appearing sequentially, occur because of the enhanced metabolism and the diminished perfusion in the intratumoral tissue. Definitely, an adequate blood supply is obligatory for brain tumor growth [13] and in case of inadequate blood supply, acidosis followed by interstitial hypoxia appears extending to the surrounding tissue, as a consequence of both elevated metabolic requirements of the proliferating tissue and impaired oxidative energy metabolism. Also, peritumoral hypoxia comes out because of direct restrainment through large sized tumors. In either case, damage sequential to glial cell swelling occurs [14] where the membranes of the cells are vulnerable for inward sodium currents augmenting the risk of epilepsy [15]. In consequence of hypoxia, glucose catabolism picks up culminating excess lactate production which leads to acidosis and in tumor tissues increased lactate levels were also shown [16]. In the peritumoral area the increase in sodium and calcium levels contribute to neuronal hyperexcitability [17] and the change in the gating of calcium channels have been reported in epileptic tissue where calcium influx is blocked via NMDA receptor channels through stabilizing the neuronal excibility by magnesium. Also, mutations in the potassium channels were implied and the extracellular potassium concentrations are known to play a role in membrane potential $[18,19]$.

Glutamate is an excitatory neurotransmitter which acts on postsynaptic membranes through interacting with ionotropic and metabotropic glutamate receptors [20]. There is a relationship 
between seizure activity and high levels of extracellular glutamate in tumor associated epilepsy. Increased levels of glutamate was shown in glioma patients with epilepsy [15,21]. The number of glutamate receptors are variable depending on the tumor degree. Ionotropic glutamate receptors, which induce intracellular calcium release when activated, are NMDA, AMPA and kainate receptors and with marred activity, in the peritumoral tissue differences in the expression are seen. GABA is also a neurotransmitter which inhibits neuronal discharge and when there is a down regulation in GABA receptors, which are GABAA, GABAB and GABAC, hyperactivity in the peritumoral zone is encountered. Alterations in the functions of GABA receptors in the peritumoral tissue, induce GABAergic neurotransmission alleviation and GABA levels are reported to be increased in tumor tissues $[18,19]$. GABAergic activity doesn't have a relationship with seizure somethesia directly yet the alterations in the levels seem causal for tumor related epilepsy. Also, in gliomas decreased kynurenic acid levels causing NMDA receptor disinhibition [22] and decreased noradrenaline and serotonin levels causing antiepileptogenic effects were reported [23].

Inflammation, either immune mediated or without infection, also play a crucial role in epileptic seizures and in tumor related epilepsy where proinflammatory cytokines being inflammatory mediators and their receptors are involved in the pathogenesis. High levels of cytokines such as interleukin (IL)-6, IL-1 $\beta$ and the IL-1, tumor necrosis factor (TNF)- $\alpha$ were implied [24]. Cytokine activation depends on both seizure severity and duration in epilepsy patients. [25, 26]. Activation of IL-1 $\beta$ system in glial cells expressing IL-1 $\beta$ and its receptor was reported in studies with chronic epileptic rats $[27,28]$. IL-4 and IL-6 were shown to be having modulating effects on neurotoxic neurotransmitters which are released during excitation and inflammation [29]. In the peritumoral tissue neurochemical alterations, coupled with the imbalance between stimulatory and inhibitory cytokines, which are immune mediated were shown in glioma [30-32] and reported to be related with tumor associated epilepsy. The activation of toll like receptor (TLR) signaling pathways, which are activated via pathogens or endogenous ligands released by damaged or stressor activated cells called as danger signals, is also a current subject in epilepsy $[33,34]$ and in neurons and astrocytes TLR4 overexpression was demonstrated in chronic epileptic mice [33,35]. The inflammation in the brain tissue is thought to be contributing to the deterioration of the blood brain barrier leading to serum albumin and IgG accumulation. Albumin was reported to be inducing the long lasting hyperexcitability via impairing astrocyte buffering capacity of extracellular potassium and glutamate through activating transforming growth factor (TGF)- $\beta$ pathway which leads to glutamate transporter downregulation [36-38]. These induced mechanisms through brain inflammation might explain the detention time occuring between the inflammatory complications and the inception of epilepsy.

\section{The redox status in brain tumors}

Brain is considered to be intensely vulnerable to oxidative damage having a high content of peroxidizable unsaturated fatty acids, high oxygen consumption per unit weight, high content of iron which is a key in lipid peroxidation and a shortage of antioxidant defense systems [39], so a crucial and unique target for both oxidative stress effects compared to other tissues and 
for metastatic growth being surrounded by the blood brain barrier. Reactive oxygen species (ROS), or free radicals, may exceed the scavenging ability of endogenous antioxidants, resulting in a shift of the redox state of the brain to the oxidative state. Redox balance in neural tissue has an important role in the pathophysiology of neurotoxicity through the free radical generation. ROS are particularly active in the brain and neuronal tissue and very aggressive to glial cells and neurons. Endogenous antioxidant system plays a constitutive role in prevention of any damage due to free radicals. However, imbalanced defense mechanism of antioxidants, overproduction or incorporation of free radicals from environment to living system bring about a serious infliction and therefore to a neuronal death [40].

Tumor cells frequently demonstrate a change in redox status. The alterations in the redox environment enhancing oxidation can induce some of the factors that cause cell proliferation and malignant transformation. Cancer cells display increased glycolysis rate combined with a reduced respiration rate [41]. The enhanced requirements for ATP; generates oxygen free radicals and this causes oxidative stress conditions to come out which eventually promotes cell death. Neurons and cancer cells consume glucose as energy source to respond this issue and glycolytic metabolism rules over in tumor cells. The release of cytochrome c couples with the pentose phosphate pathway and this initiates cytochrome c mediated apoptosis [42]. Caspase activation is initiated by cytochrome $\mathrm{c}$ when released from mitochondria during apoptosis. So, the cancer cells and neurons control apoptosis through regulation of cytochrome c release, while utilizing glucose as a source of energy [43]. This marked changes in metabolism have been shown to be related with increased oxidative stress which is emphasized to be due to increased mitochondrial superoxide radical production [44].

Studies have been done to evaluate antioxidant enzyme activities in different types of brain tumors. However, most studies have emphasized decreased levels of antioxidant enzymes and vitamins in diverse malignancies but still the results are inconsistent. Elevated manganase superoxide dismutase (MnSOD) activities were shown in the serum samples of neuroblastoma patients in a study. In recent studies, MnSOD was found to be associated with loss of differentiation and increased clinical malignancy in neuroepithelial origined brain tumors. MnSOD was found significantly positive in Grade IV astrocytomas and medulloblastomas and negative in normal brain samples. It can be said that MnSOD is overexpressed in most brain tumor types and enhanced MnSOD expression is related with a poor prognosis. MnSOD seems to be a tumor suppressor in the proliferative stage. When tumor progresses more aggressive, MnSOD is upregulated. MnSOD level positively correlates with increased metastasis so MnSOD has an oncogene role. Increase in MnSOD level was seen during the progression of different types of tumors, including brain, to the metastatic stage. Tumorigenesis and metastasis are dependent on the levels of ROS. A cell having low levels of MnSOD is vulnerable to oxidative stress then it may turn its progression to a tumor cell. Oxidative gene polymorphism and brain tumor risk seems to be associated, the increased risk of glioma and meningioma type brain tumors were found to be related with variants in some antioxidant enzyme genes and in a study, MnSOD tissue expression is said to be a prognostic marker for glioblastoma. Superoxide dismutase (SOD) and glutathione peroxidase (GPx) activities showed a clear decrease pro- 
portionally with tumor malignancy, decrease of SOD activity with the increasing grades of malignancy in brain tumors were implied $[45,46]$.

The GSH redox cycle is one of the most important antioxidative systems. GSH is a primary endogenous neuroprotectant for the brain. GSH protects neuron cells from lipid peroxidation and brain cells from peroxynitrite mediated oxidative damage. GSH is prevalantly seen in brain tissue, thus highly expressed in various primary brain tumors. GSH content was shown to be related to tumor response to nitrogen mustard therapy in human brain neoplasms. When glutathione-S-transferase (GST) isoenzymes in neoplastic and non-neoplastic astroglia were compared, GST3 isoenzyme was seen to be significantly higher in tumors. It is said that GST expression levels in brain tumors seems in association with the tumor histology as some tumor types express enhanced levels but some show only slight rise or decrease when compared to normal cells. GST was found to be active in high levels in benign tumors such as meningioma but only two-three folds higher compared to normal tissue but it was slightly increased in astrocytoma. In glioblastomas, GSH levels were found significantly lowered compared to normal tissue and merely elevated in meningioma. It has been reported that GPx and glutathione reductase (GR) enzyme activities decrease and protein oxidation levels increase in patients with glioblastoma multiforme and transitional meningioma; the two kinds of tumors which represent specially one of the most malignant and most benign tumors respectively and it was shown that there is a complex relationship between pro-and anti-apoptotic molecules in glioblastoma multiforme pathogenesis, thus targeting multiple pathways with advanced chemotherapeutic agents or radiotheraupetic regimens following total resections might be helpful in patients with glioblastoma multiforme and consistent differences in the levels of antioxidants in different types of brain tumors were emphasized in different studies. The decreased antioxidant levels in brain tumor patients reflect the enhanced oxidative damage and increased cancer developing possibility, stating the role of antioxidants in cancer prevention and role of oxidative injury as the of cancer. It was seen that $\beta$-carotene and $\alpha$-tocopherol levels decreases when malignancy grade increases and the decrease was found significant for oligodendroglioma grade I-II, glioblastoma multiforme and medulloblastoma $[45,46]$.

\section{The pivotal role of oxidative stress during epileptic seizures}

Epilepsy, being an excitotoxic brain disorder, causes neuronal destruction incrementally. The generation of ROS is distinctly implicated in a number of neurologic diseases including seizure disorders. Oxidative stress and mitochondrial dysfunction are indicated to be having a crucial role in the pathogenesis of epilepsy $[47,48]$, contributing to the neuronal destruction through the activation of proapoptotic transcription factors [49,50]. Neuronal cell damage develops due to recurrent or obstinate seizures and abnormal increases in by products during seizures through the increased metabolic activity producing ROS with damage and leading to disruption of electrophysiologic integrity and instability of neuronal membranes. $\mathrm{Fe}^{3+}$ induces oxidative damage to neuronal plasma membranes and experimentally it was shown that this is related with the development of epileptic activity. Due to small bleedings, $\mathrm{Fe}^{3+}$ levels may increase in tumoral and peritumoral areas which also prospectively contribute to the devel- 
opment of tumor related seizures and this is mostly encountered in high grade gliomas [2]. In an experimental study, intracortical injection of $\mathrm{Fe}^{3+}$ induced the formation of epileptic areas in cerebral cortex. Also, increase in the peroxidation of membrane lipids is found to be related with the development of epileptic activity [51].

Mitochondrial dysfunction is associated with epilepsy and this was demonstrated both in humans [52,53] and in several experimental epilepsy models [54,55]. When complex I was inhibited, markers of oxidative damage; 3-nitrotyrosine, 4-hydroxynonenal and protein carbonyl levels were significantly increased and this was alleviated treating with a radical scavenger and an antioxidant enzyme [56,57]. It is suggested that the reduced activity of complex I is due to oxidative modification with an extreme sensitivity to ROS, on the other hand complex I is also an important source of ROS, especially when the enzyme complex is partially inhibited [58,59]. Thereby, when complex I is inhibited, enhanced production of ROS might lead to epileptogenesis [60]. The pivotal role of mitochondrial dysfunction in the pathogenesis of epileptic seizure generation seems to be the main topic appraising oxidative stress.

\section{Contributing mitochondrial alterations}

Seizure activity is considered to be inducing energy failure and leading to neuronal injury. Neuronal mitochondria, moving along axons and dendrites, are substantially dynamic [61]. $\mathrm{Ca}^{2+}$ regulation, redox signaling, developmental and synaptic plasticity are among the functions of mitochondria [62].The triggering influence of several mutations in the genes affecting oxidative phosphorylation in epilepsy implies the importance of mitochondria for neurons. The related mutations were demonstrated in the mitochondrial DNA polymerase $\gamma$ (POLG1) [63,64], mitochondrial tRNALys (MT-TK) [65,66] and tRNAPhe (MT-TF) [67] genes in different phenotypes of epilepsy. Epilepsy is also appelled as a nonsyndromic mitochondrial disorder (MID) due to a novel classification and has a genetic or metabolic ground through a cerebral lesion or dysfunction [68]. Depending on the selection of MID patients, the prevalence seems to be lower in adulthood and the generalized seizures are remarkably more often compared to focal seizures.

Decreased ATP levels, changes in neuronal calcium homeostasis and modifications of ion channels and neurotransmitter transporters due to ROS damage are the main causes of impaired mitochondrial function and the increased neuronal excitability leading to epileptogenesis. In many studies, ATP depletion during seizures was indicated [69-71] entailing a decrease in neuronal plasma membrane potential leading to an increase in neuronal excitability as the major source of ATP for sodium potassium ATPase is the mitochondrial oxidative phosphorylation in neurons [72,73]. The interneurons, being mithochondria rich, expose a decreased synaptic transmission in inhibitory synapses, thereby the increased excitability in epilepsy due to mitochondrial dysfunction could be explained accordingly.

Mitochondria have a substantial role in intracellular $\mathrm{Ca}^{2+}$ sequestration in neurons so can be named as major calcium buffers [74,75]. Attributing to remarkable calcium flow in neuronal 
excitability, through ligand gated and voltage gated ion channels, cyclic calcium elevations are seen during epileptic activity. Referring to this, mitochondria can attenuate the altered neuronal excitability and synaptic transmission in epilepsy [76]. Yet another reason for the increased excitability encountered in epilepsy is, astroglial and neuronal glutamate transporters' being quite sensitive to oxidative damage which are known to be crucial for the maintenance of low synaptic glutamate levels [77]. and it was indicated that complex I activity induces the excess release of glutamate [78]. So it can be concluded by stating that oxidative stress has direct effects on neuronal excitability in the same time.

\section{Surgical approach}

The majority of surgical series showed that almost 60 to $90 \%$ of supratentorial benign gliomas present with epilepsy and surgical resection may be the only treatment option for both histopathological diagnosis and treatment [79]. There is still discussion whether epilepsy is a specific property of the tumor or the brain's reaction to the tumor. However, proximity to the functional areas such as primary motor strip or language or Broca's area increases the chance of having seizures. Advanced developments in the imaging technology, brain tumors, especially low-grade gliomas which were missed in the past, led the physicians to diagnose such lesions and early surgery is now performed without doubt. Since these gliomas are slow growing, seizures may occur late and any seizure in the adult life must raise the suspicion of a tumor until proven otherwise. Magnetic resonance imaging (MRI) is the gold standard diagnostic modality to diagnose brain tumors and sensitivity is higher than computerized tomography $(\mathrm{CT})$. Especially $\mathrm{T}_{2}$-weigted and FLAIR images (Figure 1) are important for visualize low grade tumors which are generally not enhanced with contrast agent. Additional imaging modalities such as MR spectroscopy may provide further evidence of the lesions true nature. In some patients electroencephalography (EEG) is needed because of discordant finding between the MRI and seizure semiology but there is no characteristic EEG pattern. However; EEG can lateralize the tumor in $70 \%$ of patients. Rarely, intracranial depth electrodes and/or electrocorticography (EcOG) is needed before and during surgery to expose the epileptogenic area. The most common location for these gliomas is the frontal lobe, followed by parietal, temporal lobes and insula. Occipital lobe alone is less involved and the reason is not clear.

Clinical experience has demonstrated that surgical removal of the lesion alone significantly reduces seizure frequency. It is interesting to note that lesionectomy alone or lesionectomy with corticectomy show similar good results so that there has been no standard resection among the centers. But we know very well that completeness of tumor removal is the most important prognostic factor for seizure control, recurrence, and improved quality of life. Surgical approach depends mainly on the proximity to the functional cortices which necessitated local anesthesia (awake craniotomy). On the other hand, when a tumor is located in silent area, general anesthesia is preferred.

Scalp incision and craniotomy is planned according to the location of the tumor and "question mark" incision has been extensively used for temporal, frontal tumors (Figure 2). For central 


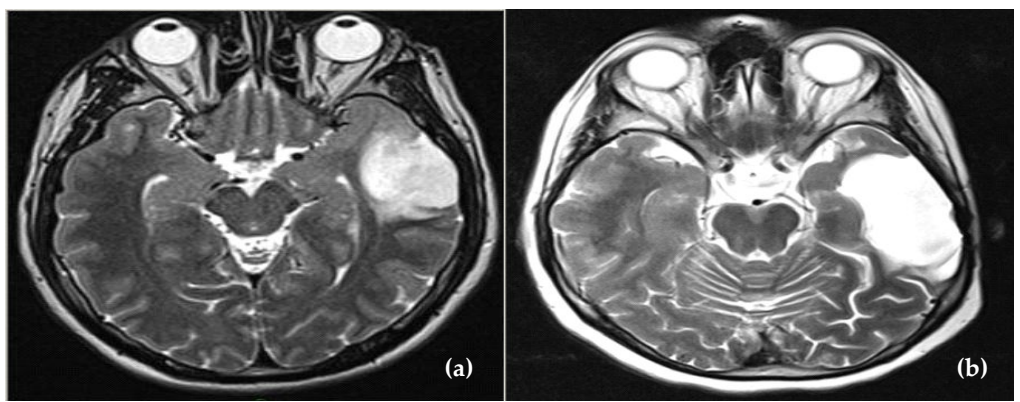

Figure 1. This 27-year-old male was presented with complex-partial seizure and MRI showed a mass in the left temporal lobe without involvement of the mesial temporal structures (hippocampus, parahippocampus and amygdala). The tumor margin is clearly seen in the preopretive $\mathrm{T}_{2}$-weighted image (a) and histopathological diagnosis was astrocytoma grade-II and 3 years after the surgery the $T_{2}$-weighted image (b) shows no tumor recurrence and the patients is seizure free without antiepileptic medication.

and parietal located tumors an inverted"U-shaped" incision is usually sufficient. Particular attention should be paid to dural sinuses and large cortical veins when removing the bone flap and opening the dura. If awake craniotomy is performed, cortical mapping with intraoperative electrical cortical stimulation in order to figure out the functional area should be performed. The aim of the cortical mapping is to have maximum tumor removal with minimum neurological deficit by not causing any damage to the functional cortex (Figure 3).

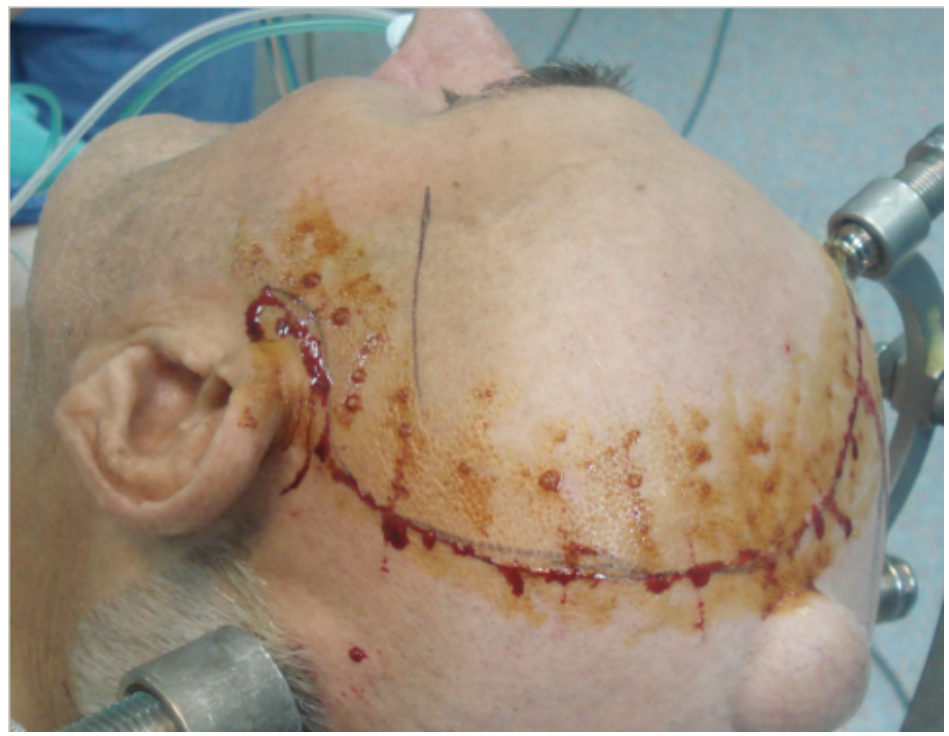

Figure 2. The picture showing a "question mark" scalp incision which is the commonest incision type used in the neurosurgical operations. 


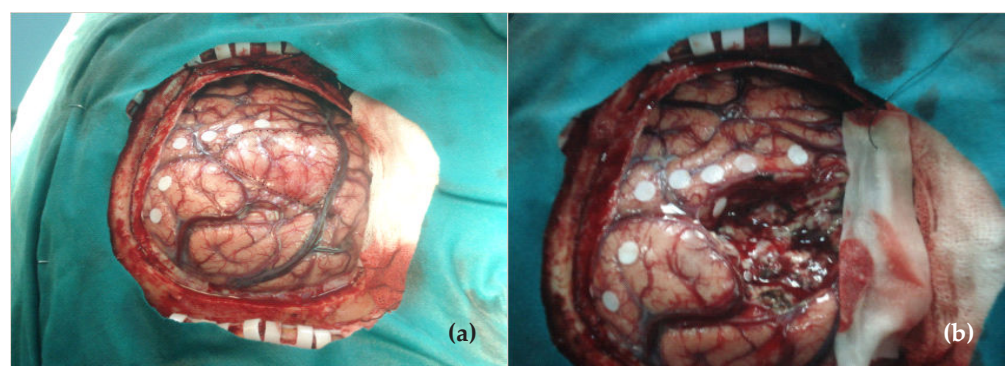

Figure 3. This picture shows an awake craniotomy and intraoperative electrical cortical stimulation (cortical mapping) for the identification of the motor cortex (white paper marks) which is close to the tumor (black dots depict the tumor) (a). The tumor was removed without any motor deficits (b) and the patient is seizure free at 1 year follow up.

The main surgical technique for the removal of these gliomas is "endopial" resection. By doing this technique, vessels running deep in the sulci and neighboring cortices are saved. Since these tumors are surrounded by the pial layers, respecting the pia avoids severe neurovascular damage during surgery and minimizes postoperative neurological deficits.

\section{Potential neuroprotective and therapeutic strategies in tumor related epilepsy}

Epileptic seizures related to brain tumors generally expose kind of focal seizures and around one third of the patients are resistive to medical antiepileptic treatment. Generally, neuronal voltage gated sodium and calcium channels, glutamate receptors and the GABA system are the main targets for antiepileptic drugs (AED) [80] which usually trend to treat through several mechanisms suppressing abnormal neuronal set off, solely none of the medications seems to be exhibiting an alteration neither in the progress of the disease not in the prevention [81] due to a number of reasons involving the biochemical context of the peritumoral zone and the drug drug interactions between the chemotherapeutics and AEDs inspiring an antiepileptic effectiveness revealing some side effects [82]. Also, the overexpression of the multidrug resistance proteins (MRPs) in tumors may restrict medicine diffusion into the brain as increased levels of MRPs were reported in brain tumor cells [82]. AEDs are known to be leading to cognitive impairment [83]. Moreoever, some patients under AED therapy exhibit poor seizure control as well as with undesireable side effects [84] embracing a high risk of teratogenicity in women [85], alterations in mood, hepatotoxicity, decrease in the mineral density of the bone, difficulties in weight management, dermal maladies etc. [86], thereby an increased tolerability towards new desiged AEDs should be the main intention in future studies. Currently, development of novel glial specific AEDs is considered to be a potential target promising to improve a good outcome.

Obviously, epileptogenesis is intimately associated with oxidative stress inducing ROS generation thus leading to membrane lipid peroxidation and impairment in the antioxidant 
defense system which also increase the risk of seizure recurrence [87]. In case, treatment with antioxidants is considered to be very profitable in inhibiting epileptic seizures without any adverse effect [88]. Selenium, an antioxidant protecting against ROS, is known to be causing an alteration in the rate of some neurotransmitters when deficient and depletion in selenium levels was reported to be leading to a failure in response to AEDs which act through GABAergic receptors due to an increased glutamate receptor activation [89] and utilization of selenium supplements reduce epileptic seizures [90]. Application of resveratrol, a meritorious antioxidant, was also demonstrated to be useful in seizure management and in reducing seizure incidence [91]. Similar findings were indicated experimentally where the prevention of seizures was concerned [92,93] Thymoquinone, another potent free radical and superoxide radical scavenger, exhibited an antiepileptic effect in children suggesting a lack of adverse effects even at high doses [94]. With respect to this point of view, the antiepileptic effect of curcumin, which is an active polyphenolic component, extracted from Curcuma longa called as turmeric, was also investigated being almost ten times more active than vitamin $\mathrm{E}$ as an antioxidant [95]. Implementation of curcumin which inhibits the transcription of inflammatory cytokines via nuclear factor kappa B (NF- $\kappa$ B),inducible nitric oxide synthase (iNOS), and cyclooxygenase 2 (Cox-2) [96], was demonstrated to be preventing the cognitive decline related to traumatic brain injury [97] and its antiepileptic potential was ascertained with short term treatment. Recently, inhibitors of mammalian target of rapamycin (mTOR), including rapamycin and its analogs, are pointed out and regular treatment with rapamycin is emphasized in preventing epileptogenesis experimentally [98,99], thereby, research relevant to inhibiting mTOR activity seems appreciable. Curcumin is also suggested as mTOR inhibitor suppressing epileptogenesis in experimental studies [100,101].

The ketogenic diet (KD), a subdued carbohydrate diet, is known to be effective in epilepsy treatment [102-104] being neuroprotective and antiepileptogenic. In children, seizures owing to GLUT-1 and pyruvate dehydrogenase deficiency are treated with KD [105], also a prosperous outcome is seen with other pediatric epilepsy syndromes [106] as it upregulates the neuronal gene expression of the enzymes in Krebs cyclus, oxidative phosphorylation and glycolysis and increases mitochondria density leading to enhanced brain metabolism $[107,108]$, therefore, stimulating the Krebs cyclus seems to be an attractive strategy in seizure management via direct replenishment of energy substrates $[109,110]$. $\beta$-hydroxybutyrate, being a ketone body, protects against metabolic and excitotoxic insults in organotypic hippocampal cultures [111]. Considering the nutrient and energy sensing ability of mTOR, it has a role in pathophysiologic changes related to epileptogenesis and mTOR activity is increased after epileptic status. KD reducing the insulin levels [112], is expected to be inhibiting mTOR activity through decreasing the PI3K/Akt signaling pathway. Also, ROS have a role in the efficacy of KD as the production of some mitochondrial uncoupling proteins are increased with KD and this eventuates with a reduction in the mitochondrial membrane potential and an increase in mitochondrial respiration rate [113]. Mitochondrial production of ROS is decreased with ketone bodies via increasing NADH oxidation without affecting endogenous antioxidant glutathione levels [114]. It was shown that in rat neocortical neurons, ketones prevent oxidative injury via decreasing mitochondrial ROS production [115]. Recently, pyruvate seems to be a promising substrate on seizure activity due to its dual action as a 
scavenger of ROS and a substrate of Krebs cyclus, so as a strategy in treatment, this might be taken into consideration in prolonged seizures [116]. Restricted KD was implied to be an alternative approach in brain cancer management also, with the purpose of changing the metabolic environment of the tumor [117], yet further studies are essential in case the glucose levels of the patients are lowered when simultaneously the ketone levels are elevated, in the lack of radiation or drug toxicity.

Currently, the role of microRNAs (miRNA) is emphasized in the regulation of immune responses. miR-146a, known to be induced via several proinflammatory cytokines such as IL-1 $\beta$ and TNF- $\alpha$, was shown to be upregulating in experimental epilepsy models $[118,119]$, thereby miRNA is suggested to be a potential target in modulating the inflammatory pathways. Some inflammatory mediators have direct effects on neuronal excitability providing a decrease in seizure threshold which was demonstrated experimentally, so if the activation of inflammatory signalings might be blocked, this may also be appraised as a possible therapeutic approach for epilepsy patients.

Distinctive medications exhibit variable therapeutic approaches for epilepsy patients. Not only improving seizure management but also preventing epilepsy in patients who have high risk should be the main target in the treatment with antiepileptogenics. Future studies are truly required with an acceptable safety profile, especially for herbal and supplemental products as there is an incompetence of relevant clinical results although they are recommended in seizure treatment. Yet, antioxidant compounds, particulary targeting mitochondria, may have beneficial effects on long term consequences of epilepsy.

\section{Conclusion}

Epileptic seizures are common in patients with brain tumors. The mechanisms laying beneath the pathogenesis of tumor related epilepsy remain substantially unclear. Epileptogenicity might be generated by the tumor itself because of the intrinsic characteristics or the impaired balance between excitation and inhibition arising due to insufficient homeostasis in the peritumoral zone might be the reason where also metabolic, immunological and inflammatory alterations might be contributing. Thereby, clarifying both tumoral and peritumoral pathophysiology would lead in selecting the most convenient medical treatment. Recently, oxidative stress is suggested to be having a crucial role in brain tumor associated epileptic seizures as a means of mitochondrial dysfunction. Yet it should be enlightened with future studies weather treatment with antioxidant compounds would be beneficial on attenuating epileptic seizures. On the other hand, as there are no detectable inflammatory biomarkers with proven significance for epilepsy yet, the challenge should also be defining specific biomarkers which would be helpful in the diagnosis of antiinflammatory or immunomodulatory therapy effects. Apparently, bringing novel concepts out in the treatment strategies for brain tumor related epilepsy should be the main target in the future. 


\section{Acknowledgements}

We would like to dedicate this chapter to patients having brain tumors suffering from epilepsy seizures.

\section{Author details}

Pinar Atukeren ${ }^{1}$, Taner Tanriverdi² and M. Ramazan Yigitoglu ${ }^{3}$

1 Istanbul University, Cerrahpasa Medical Faculty, Department of Biochemistry, Istanbul, Turkey

2 Istanbul University, Cerrahpasa Medical Faculty, Department of Neurosurgery, Istanbul, Turkey

3 Turgut Ozal University, Faculty of Medicine, Department of Biochemistry, Ankara, Turkey

\section{References}

[1] Lote K, Stenwig AE, Skullerud K, Hirschberg H. Prevalence and prognostic significance of epilepsy in patients with gliomas. Eur J Cancer 1998;34 98-102.

[2] You G, Sha Z, Jiang T. The pathogenesis of tumor-related epilepsy and its implications for clinical, treatment. Seizure 2012;21:153-159.

[3] Chao CC, Molitor TW, Hu S. Neuroprotective role of IL-4 against activated microglia. J Immunol. 1993;151:1473-81.

[4] Hulkkonen J, Koskikallio E, Rainesalo S, Keranen T, Hurme, M, Peltola J. The balance of inhibitory and excitatory cytokines is differently regulated in vivo and in vitro among therapy resistant epilepsy patients. Epilepsy Res. 2004;59:199-205.

[5] Vezzani A, French J, Bartfai T, Baram TZ. The role of inflammation in epilepsy. Nat. Rev. Neurol. 2011;7:31-40.

[6] Vezzani A, Maroso M, Balosso S, Sanchez MA, Bartfai T. IL-1 receptor/Toll-like receptor signaling in infection, inflammation, stress and neurodegeneration couples hyperexcitability and seizures. Brain Behav. Immun. 2011;25 (7):1281-1289.

[7] Chernov MF, Kubo O, Hayashi M, Izawa M, Maruyama T, Usukura M, et al. Proton MRS of the peri-tumoral brain. J Neurol Sci 2005;228:137-42.

[8] Norden AD, Blumenfeld $H$. The role of subcortical structures in human epilepsy. Epilepsy Behav 2002;3:219-31. 
[9] Wolf HK, Roos D, Blumcke I, Pietsch T, Wiestler OD. Perilesional neurochemical changes in focal epilepsies. Acta Neuropathol 1996;91:376-84.

[10] Vecht CJ, van Breemen M. Optimizing therapy of seizures in patients with brain tumors. Neurology 2006;67:S10-3.

[11] Liebner S, Fischmann A, Rascher G, Duffner F, Grote EH, Kalbacher H, et al. Claudin-1 and claudin-5 expression and tight junction morphology are altered in blood vessels of human glioblastoma multiforme. Acta Neuropathol 2000;100:323-31.

[12] Chi OZ, Hunter C, Liu X, Tan T, Weiss HR. Effects of VEGF on the blood- brain barrier disruption caused by hyperosmolarity. Pharmacology 2008;82:187-92.

[13] Fidler IJ, Yano S, Zhang RD, Fujimaki T, Bucana CD. The seed and soil hypothesis: vascularization and brain metastasis. Lancet Oncol 2002;3:53-7.

[14] Kempski O, Staub F, Jansen M, Schodel F, Baethmann A. Glial swelling during extracellular acidosis in vitro. Stroke 1988;19:385-92.

[15] Schaller B. Influences of brain tumor-associated $\mathrm{pH}$ changes and hypoxia on epileptogenesis. Acta Neurol Scand 2005;111:75-83.

[16] Martinez-Outschoorn UE, Prisco M, Ertel A, Tsirigos A, Lin Z, Pavlides S, et al. Ketones and lactate increase cancer cell stemness, driving recurrence, metastasis and poor clinical outcome in breast cancer. Cell Cycle 2011;10:1271-86.

[17] Hossmann KA, Seo K, Szymas J, Wechsler W. Quantitative analysis of experimental peri-tumoral edema in cats. Adv Neurol 1990;52:449-58.

[18] Avoli M, Louvel J, Pumain R, Kohling R. Cellular and molecular mechanisms of epilepsy in the human brain. Prog Neurobiol 2005;77:166-200.

[19] Badawy RA, Harvey AS, Macdonell RA. Cortical hyperexcitability and epileptogenesis: understanding the mechanisms of epilepsy-part 1. J Clin Neurosci 2009;16:35565.

[20] Xiao MY, Gustafsson B, Niu YP. Metabotropic glutamate receptors in the trafficking of ionotropic glutamate and GABAA receptors at central synapses. Curr Neuropharmacol 2006;4:77-86.

[21] Bateman DE, Hardy JA, McDermott JR, Parker DS, Edwardson JA. Amino acid transmitter levels in gliomas and their relationship to the incidence of epilepsy. Neurol Res 1988;10:112-4.

[22] Vezzani A, Gramsbergen JB, Speciale C, Schwarcz R. Production of quinolinic acid and kynurenic acid by human gliomas. Adv Exp Med Biol 1991;294: 691-5.

[23] Haglund MM, Berger MS, Kunkel DD, Franck JE, Ghatan S, Ojemann GA. Changes in gamma-aminobutyric acid and somatostatin in epileptic cortex associated with low-grade gliomas. J Neurosurg 1992;77:209-16. 
[24] Aronica E, Crino PB. Inflammation in epilepsy: clinical observations. Epilepsia 2011;52 (3):26-32.

[25] Alapirtti T, Rinta S, Hulkkonen J, Makinen R, Keranen T, Peltola J. Interleukin-6, interleukin-1 receptor antagonist and interleukin-1beta production in patients with focal epilepsy: a video-EEG study. J. Neurol. Sci. 2009;280:94-97.

[26] Bauer S, Cepok S, Todorova-Rudolph A, Nowak M, Koller M, Lorenz R, Oertel WH, Rosenow F, Hemmer B, Hamer HM. Etiology and site of temporal lobe epilepsy influence postictal cytokine release. Epilepsy Res. 2009;86:82-88.

[27] Ravizza T, Vezzani A. Status epilepticus induces time-dependent neuronal and astrocytic expression of interleukin-1 receptor type I in the rat limbic system. Neuroscience 2006;137:301-308.

[28] Ravizza T, Gagliardi B, Noé F, Boer K, Aronica E, Vezzani A. Innate andadaptive immunity during epileptogenesis and spontaneous seizures: evidence from experimental models and human temporal lobe epilepsy. Neurobiol. Dis. 2008;29:142-160.

[29] Brenner AV, Butler MA, Wang SS, Ruder AM, Rothman N, Schulte PA, et al. Singlenucleotide polymorphisms in selected cytokine genes and risk of adult glioma. Carcinogenesis 2007;28:2543-7.

[30] Chao CC, Molitor TW, Hu S. Neuroprotective role of IL-4 against activated microglia. J Immunol 1993;151:1473-81.

[31] Block ML, Zecca L, Hong JS. Microglia-mediated neurotoxicity: uncovering the molecular mechanisms. Nat Rev Neurosci 2007;8:57-69.

[32] Hulkkonen J, Koskikallio E, Rainesalo S, Keranen T, Hurme M, Peltola J. The balance of inhibitory and excitatory cytokines is differently regulated in vivo and in vitro among therapy resistant epilepsy patients. Epilepsy Res 2004;59:199-205.

[33] Maroso M, Balosso S, Ravizza T, Liu J, Aronica E, Iyer AM, Rossetti C, Molteni M, Casalgrandi M, Manfredi AA, Bianchi ME, Vezzani A. Toll-like receptor 4 and highmobility group box-1 are involved in ictogenesis and can be targeted to reduce seizures. Nat. Med. 2010;16:413-419.

[34] Riazi K, Galic MA, Pittman QJ. Contributions of peripheral inflammation to seizure susceptibility: cytokines and brain excitability. Epilepsy Res. 2010;89:34-42.

[35] Zurolo E, Iyer A, Maroso M, Carbonell C, Anink JJ, Ravizza T, Fluiter K, Spliet GWM, van Rijen PC, Vezzani A, Aronica E. Activation of TLR, RAGE and HMGB1 signaling in malformations of cortical development. Brain 2011;134: 1015-1032.

[36] Cacheaux LP, Ivens S, David Y, Lakhter AJ, Bar-Klein G, Shapira M, Heinemann U, Friedman A, Kaufer D. Transcriptome profiling reveals TGF-beta signaling involvement in epileptogenesis. J. Neurosci. 2009;29:8927-8935. 
[37] Friedman A, Kaufer D, Heinemann U. Blood-brain barrier breakdown-inducing astrocytic transformation: novel targets for the prevention of epilepsy. Epilepsy Res. 2009;85:142-149.

[38] Shlosberg D, Benifla M, Kaufer D, Friedman A. Blood-brain barrier breakdown as a therapeutic target in traumatic brain injury. Nat. Rev. Neurol. 2010;6:393-403.

[39] Floyd RA. Antioxidants, oxidative stress, and degenerative neurological disorders, Proc Soc Exp Biol Med, Vol. 1999;222(3):236- 45

[40] Halliwell B. Role of free radicals in the neurodegenerative diseases: therapeuti implications for antioxidant treatment, Drugs Aging 2001;18:685-716.

[41] Spitz DS, Sim JE, Ridnour LA, Galoforo SS, Lee YJ. Glucose deprivation-induced oxidative stress in human tumor cells: a fundamental defect in metabolism?, Ann. N. Y. Acad. Sci. 2000;899:349-362.

[42] Vaughn AE, Deshmukh M. Glucose metabolism inhibits apoptosis in neurons and cancer cells by redoxin activation of cytochrome c, Nature Cell Biology 2008;10:1477-1483.

[43] Dajas F. Life or death:Neuroprotective and anti cancer effects of quercetin, Journal of Ethnopharmacology 2012;143(2):383-96.

[44] Oberley LW, Oberley TD, Buettner GR. Cell division in normal and transformed cells: the possible role of superoxide and hydrogen peroxide. Med. Hypoth. 1981;7:21-42.

[45] Atukeren P. The impact of redox balance in brain tumors. In: Garami M. (ed.) Molecular Targets Of CNS Tumors. InTech: 2012. p663- p674.

[46] Atukeren P., Yigitoglu MR. The stance of antioxidants in brain tumors. In: Lichter T. (ed.) Clinical Management And Evolving Novel Therapeutic Strategies For Patients With Brain Tumors. InTech: 2013. p523- p551.

[47] Kudin AP, Zsurka G, Elger CE, Kunz WS. Mitochondrial involvement in temporal lobe epilepsy. Exp. Neurol. 2009;218;326-332.

[48] Waldbaum S, Patel M. Mitochondria, oxidative stress, and temporal lobe epilepsy. Epilepsy Res. 2010;88:23-45.

[49] Schweizer U, Brauer AU, Kohrle J, Nitsch R, Savaskan NE. Selenium and brain function: A poorly recognized liaison. Brain Res Rev 2004;45:164-78.

[50] Savaskan NE, Brauer AU, Kuhbacher M, et al. Selenium deficiency increases susceptibility to glutamate-induced excitotoxicity. FASEB J 2003;17:112-4.

[51] Ashrafi MR, Shabanian R, Abbaskhanian A, Nasirian A, Ghofrani M, Mohammadi M, Zamani GR, Kayhanidoost Z, Ebrahimi S, Pourpak Z. Selenium and intractable epilepsy: is there any correlation? Pediatr Neurol. 2007;36(1):25-9. 
[52] Kunz WS, Kudin AP, Vielhaber S, Blümcke I, Zuschratter W, Schramm J, Beck H, Elger CE. Mitochondrial complex I deficiency in the epileptic focus of patients with temporal lobe epilepsy. Ann. Neurol. 2000;48:766-773.

[53] Lee YM, Kang HC, Lee JS, Kim SH, Kim EY, Lee SK, Slama A, Kim HD. Mitochondrial respiratory chain defects: underlying etiology in various epileptic conditions. Epilepsia 2008;49:685-690.

[54] Chuang YCh, Chang AYW, Lin JW, Hsu SP, Chan SHH. Mitochondrial dysfunction and structural damage in the hippocampus during kainic acid-induced status epilepticus in the rat. Epilepsia 2004;45:1202-1209.

[55] Sleven H, Gibbs JE, Heales S, Thom M, Cock HR. Depletion of reduced glutathione precedes inactivation of mitochondrial enzymes following limbic status epilepticus in the rat hippocampus. Neurochem. Int. 2006;48:75-82.

[56] Folbergrová J, Ješina P, Drahota Z, Lisý V, Haugvicová R, Vojtíšková A, Houštěk J. Mitochondrial complex I inhibition in cerebral cortex of immature rats following homocysteic acid-induced seizures. Exp. Neurol. 2007;204: 597-609.

[57] Folbergrová J, Ješina P, Haugvicová R, Lisý V, Houštěk J. Sustained deficiency of mitochondrial complex I activity during long periods of survival after seizures induced in immature rats by homocysteic acid. Neurochem. Int. 2010;56:394-403.

[58] Fato R, Bergamini C, Leoni S, Strocchi P, Lenaz G. Generation of reactive oxygen species by mitochondrial complex I: implications in neurodegeneration. Neurochem. Res. 2008;33:2487-2501.

[59] Kudin AP, Bimpong-Buta NY, Vielhaber S, Elger CE, Kunz WS. Characterization of superoxide-producing sites in isolated brain mitochondria. J. Biol. Chem. 2004;279:4127-4135.

[60] Folbergrová J, Otáhal J, Druga R, Tsenov G, Haugvicová R, Kubová H. Effect of (S)-3,4 dicarboxyphenylglycine on epileptogenesis and cognitive impairment following seizures induced in immature rats by homocysteic acid. Epilepsia 2009;50(10): 335.

[61] Hollenbeck PJ, Saxton WM. The axonal transport of mitochondria. J. Cell Sci. 2005;118:5411-5419.

[62] Mattson MP, Gleichmann M, Cheng A. Mitochondria in neuroplasticity and neurological disorders. Neuron 2008;60:748-766.

[63] Zsurka G, Baron M, Stewart JD, Kornblum C, Bös M, Sassen R, Taylor RW, Elger CE, Chinnery PF, Kunz WS. Clonally expanded mitochondrial DNA mutations in epileptic individuals with mutated DNA polymerase gamma. J. Neuropathol. Exp. Neurol. 2008;67:857-866. 
[64] Naviaux RK, Nguyen KV. POLG mutations associated with Alpers' syndrome and mitochondrial DNA depletion. Ann. Neurol. 2004;55:706-712.

[65] Zsurka G, Hampel KG, Nelson I, Jardel C, Mirandola SR, Sassen R, Kornblum C, Marcorelles P, Lavoué S, Lombès A, Kunz WS. Severe epilepsy as the major symptom of new mutations in the mitochondrial tRNA(Phe) gene. Neurology 2010;74:507512.

[66] Zeviani M, Muntoni F, Savarese N, Serra G, Tiranti V, Carrara F, Mariotti C, DiDonato $S$. A MERRF/MELAS overlap syndrome associated with a new point mutation in the mitochondrial DNA tRNA(Lys) gene. Eur. J. Hum. Genet. 1993;1:80-87.

[67] Shoffner JM, Lott MT, Lezza AM, Seibel P, Ballinger SW, Wallace DC. Myoclonic epilepsy and ragged-red fiber disease (MERRF) is associated with a mitochondrial DNA tRNA(Lys) mutation. Cell 1990;61:931-937.

[68] Finsterer J, Jarius C, Eichberger H. Phenotype variability in 130 adult patients with respiratory chain disorders. Journal of Inherited Metabolic Disease 2001;224:560-76.

[69] Dale N, Frenguelli BG. Release of adenosine and ATP during ischemia and epilepsy. Curr. Neuropharmacol. 2009;7:160-179.

[70] Kovac S, Domijan AM, Walker MC, Abramov AY. Prolonged seizure activity impairs mitochondrial bioenergetics and induces cell death. J Cell Sci. 2012;1(125):1796-806.

[71] Wasterlain CG, Thompson KW, Suchomelova L, Niquet J. Brain energy metabolism during experimental neonatal seizures. Neurochem. Res. 2010;35:2193-2198.

[72] Astrup J, Sorensen PM, Sorensen HR. Oxygen and glucose consumption related to $\mathrm{Na}+-\mathrm{K}+$ transport in canine brain. Stroke 1981;12:726-730.

[73] Ames A. CNS energy metabolism as related to function. Brain Res. Rev. 2000;34:4268.

[74] Tang YG, Zucker RS. Mitochondrial involvement in post-tetanic potentiation of synaptic transmission. Neuron 1997;18:483-491.

[75] Duchen MR. Mitochondria and calcium: from cell signaling to cell death. J. Physiol. (London) 2000;529:57-68.

[76] Bindokas VP, Lee CC, Colmers WF, Miller RJ. Changes in mitochondrial function resulting from synaptic activity in the rat hippocampal slice. J. Neurosci. 1998;18:4570 4587.

[77] Trotti D, Danbolt NC, Voltera A, Glutamate transporters are oxidantvulnerable: a molecular link between oxidative and excitotoxic neurodegeneration? Trends Pharmacol. Sci. 1998;19:328-334. 
[78] Kilbride SM, Telford JE, Tipton KF, Davey GP. Partial inhibition of complex I activity increases Ca-independent glutamate release rates from depolarized synaptosomes. J. Neurochem. 2008;106:826-834.

[79] Olivier A, Boling WW, Tanrıverdi T. Surgical Techniques in Epilepsy Surgery: The MNI Approach. Cambridge University Press, UK; 2012.

[80] Rogawski MA, Löscher W. The neurobiology of antiepileptic drugs. Nat. Rev. Neurosci. 2004;5:553-564.

[81] Temkin NR. Antiepileptogenesis and seizure prevention trials with antiepileptic drugs: meta-analysis of controlled trials, Epilepsia 2001;42:515-524.

[82] Loscher W. How to explain multidrug resistance in epilepsy? Epilepsy Curr 2005;5:107-12.

[83] Aldenkamp AP, De Krom M, Reijs R. Newer antiepileptic drugs and cognitive issues. Epilepsia 2003;44:21-29.

[84] Perucca E. An introduction to antiepileptic drugs. Epilepsia 2005;46:31-37.

[85] Wlodarczyk BJ, Palacios AM, George TM, Finnell RH. Antiepileptic drugs and pregnancy outcomes. Am. J. Med. Genet. 2012;58:2071-2090.

[86] Perucca P, Gilliam FG. Adverse effects of antiepileptic drugs. Lancet Neurol. 2012;11:792-802.

[87] Maertens P, Dyken P, Graf W, Pippenger C, Chronister R, Shah A. Free radicals, anticonvulsants, and the neuronal ceroid-lipofuscinoses. Am J Med Genet 1995;57:225-8.

[88] Mori A, Yokoi I, Noda Y, Willmore LJ. Natural antioxidants may prevent posttraumatic epilepsy: a proposal based on experimental animal studies. Acta Med Okayama 2004;58:111-8.

[89] Savaskan NE, Brauer AU, Kuhbacher M, et al. Selenium deficiency increases susceptibility to glutamate-induced excitotoxicity. FASEB J 2003;17:112-4.

[90] Ramaekers VT, Calomme M, Vanden Berghe D, Makropoulos W. Selenium deficiency triggering intractable seizures. Neuropediatrics 1994;25:217-23.

[91] Shetty AK. Promise of resveratrol for easing status epilepticus and epilepsy. Pharmacology Therapeutics 2011;131:269-86.

[92] Wu Z, Xu Q, Zhang L, Kong D, Ma R, Wang L. Protective effect of resveratrol against kainate-induced temporal lobe epilepsy in rats. Neurochemical Research 2009;34:1393-400.

[93] Gupta YK, Chaudhary G, Srivastava AK. Protective effect of resveratrol against pentylenetetrazole-induced seizures and its modulation by an adenosinergic system. Pharmacology 2002;65:170-4. 
[94] Akhondian J, Kianifar H, Raoofziaee M, Moayedpour A, Toosi MB, Khajedaluee M. The effect of thymoquinone on intractable pediatric seizures (pilot study). Epilepsy Res 2011;93:39-43.

[95] Khopde SM, Priyadarsini KI, Mukherjee T, Kulkarni PB, Satav JG, Bhattacharya RK. Does beta-carotene protect membrane lipids from nitrogen dioxide? Free Radic Biol Med 1998;25:66-71.

[96] Plummer SM, Holloway KA, Manson MM, et al. Inhibition of cyclo-oxygenase 2 expression in colon cells by the chemopreventive agent curcumin involves inhibition of NF-kB activation via the NIK/IKK signaling complex. Oncogene 1999;18:6013-20.

[97] Wu A, Molteni R, Ying Z, Gomez-Pinilla F. A saturated-fat diet aggravates the outcome of traumatic brain injury on hippocampal plasticity and cognitive function by reducing brain-derived neurotrophic factor. Neuroscience 2003;119:365-75.

[98] Huang X, Zhang H, Yang J, Wu J, McMahon J, Lin Y, Cao Z, Gruenthal M, Huang Y. Pharmacological inhibition of the mammalian target of rapamycin pathway suppresses acquired epilepsy, Neurobiol. Dis. 2010;(40):193-199.

[99] Zeng LH, Xu L, Gutmann DH, Wong M. Rapamycin prevents epilepsy in a mouse model of tuberous sclerosis complex, Ann. Neurol. 2008;63:444-453.

[100] Beevers CS, Chen L, Liu L, Luo Y, Webster NJG, Huang S. Curcumin disrupts the mammalian target of rapamycin-raptor complex, Cancer Res. 2009;69:1000-1008.

[101] Jyoti A, Sethi P, Sharma D. Curcumin protects against electrobehavioral progression of seizures in the iron-induced experimental model of epileptogenesis, Epilepsy Behav. 2009;14:300-308.

[102] Marsh EB, Freeman JM, Kossoff EH, Vining EP, Rubenstein JE, Pyzik PL, Hemingway C. The outcome of children with intractable seizures: a 3-to 6-year follow-up of 67 children who remained on the ketogenic diet less than one year, Epilepsia 2006;47:425-430.

[103] Neal EG, Chaffe H, Schwartz RH, Lawson MS, Edwards N, Fitzsimmons G, Whitney $\mathrm{A}, \mathrm{Cross} \mathrm{JH}$. The ketogenic diet for the treatment of childhood epilepsy: a randomised controlled trial, Lancet Neurol. 2008;7:500-506.

[104] Patel A, Pyzik PL, Turner Z, Rubenstein JE, Kossoff EH. Long-term outcomes of children treated with the ketogenic diet in the past, Epilepsia 2010;51:1277-1282.

[105] Freeman JM, Kossoff EH. Ketosis and the ketogenic diet, 2010: advances in treating epilepsy and other disorders. Adv. Pediatr. 2010;57:315-329.

[106] Cross JH, McLellan A, Neal EG, Philip S, Williams E, Williams RE. The ketogenic diet in childhood epilepsy: where are we now? Arch. Dis. Child. 2010;95:550-553.

[107] Bough K. Energy metabolism as part of the anticonvulsant mechanism of the ketogenic diet. Epilepsia 2008;49(8):91-93. 
[108] Bough KJ, Wetherington J, Hassel B, Pare JF, Gawryluk JW, Greene JG, Shaw R, Smith Y, Geiger JD, Dingledine RJ. Mitochondrial biogenesis in the anticonvulsant mechanism of the ketogenic diet. Ann. Neurol. 2006;60:223-235.

[109] Borges K, Sonnewald U. Triheptanoin-A medium chain triglyceride with odd chain fatty acids: a new anaplerotic anticonvulsant treatment? Epilepsy Res 2011;100(3): 239-44.

[110] Shorvon S, Ferlisi M. The treatment of super-refractory status epilepticus: a critical review of available therapies and a clinical treatment protocol. Brain 201;134:2802-2818.

[111] Samoilova M, Weisspapir M, Abdelmalik P, Velumian, AA, Carlen PL. Chronic in vitro ketosis is neuroprotective but not anti-convulsant, J. Neurochem. 2010;113:826835 .

[112] Thio LL, Erbayat-Altay E, Rensing N, Yamada KA. Leptin contributes to slower weight gain in juvenile rodents on a ketogenic diet, Pediatr. Res. 2006;60:413-417.

[113] Sullivan PG, Rippy NA, Dorenbos K, Concepcion RC, Agarwal AK, Rho JM. The ketogenic diet increases mitochondrial uncoupling protein levels and activity. Ann. Neurol. 2004;55:576-580.

[114] Maalouf M, Sullivan PG, Davis L, Kim DY, Rho JM. Ketones inhibit mitochondrial production of reactive oxygen species production following glutamate excitotoxicity by increasing NADH oxidation. Neuroscience 2007;145:256-264.

[115] Kim DY, Rho JM. The ketogenic diet and epilepsy. Curr. Opin. Clin. Nutr. Metab. Care 2008;11:113-120.

[116] Norwood BA, Bauer S, Wegner S, Hamer HM, Oertel WH, Sloviter RS, Rosenow F. Electrical stimulation-induced seizures in rats: a "doseresponse" study on resultant neurodegeneration. Epilepsia 2011;52:109-112.

[117] Seyfried TN, Kiebish MA, Marsh J, Shelton LM, Huysentruyt LC, Mukherjee P. Metabolic management of brain cancer. Biochim Biophys Acta. 2011;1807(6):577-94.

[118] Aronica E, Fluiter K, Iyer A, Zurolo E, Vreijling J, van Vliet EA, Baayen JC, Gorter JA. Expression pattern of miR-146a, an inflammation-associated microRNA, in experimental and human temporal lobe epilepsy. Eur. J. Neurosci. 2010;31:1100-1107.

[119] Song YJ, Tian XB, Zhang S, Zhang YX, Li X, Li D, Cheng Y, Zhang JN, Kang CS, Zhao W. Temporal lobe epilepsy induces differential expression of hippocampal miRNAs including let-7e and miR-23a/b. Brain Res. 2011;1387:134-140. 
